\title{
Canada's Marihuana for Medical Purposes Regulations: a synopsis for health professionals
}

\author{
Daniel Ziemianski ${ }^{1}$, Mark A. Ware ${ }^{* 1,2}$ \\ ${ }^{1}$ Canadian Consortium for the Investigation of Cannabinoids, Montreal, Quebec, Canada \\ ${ }^{2}$ Alan Edwards Pain Management Unit, McGill University Health Centre, Montreal, Quebec, Canada
}

Received: May 12, 2015

DOI: $10.5430 /$ jha.v4n5p79
Accepted: July 5, 2015

Online Published: July 23, 2015

\begin{abstract}
Cannabis for therapeutic purposes (medical marijuana) is a complex reality in many parts of the world. Laws and regulations surrounding cannabis for therapeutic purposes around the world are evolving. The Marihuana for Medical Purposes Regulations (MMPR) define roles and responsibilities pertaining to cannabis for therapeutic purposes in Canada. These regulations are lengthy and technical but include information important to health professionals. This article presents a synopsis of elements within the regulations that are important for health professionals. The purpose of this paper is to assist health professionals to understand the structure and impact of these regulations. With a greater understanding of how cannabis for therapeutic purposes is regulated, health professionals will be capable of engaging in more informed discussions with patients and colleagues, and will be better equipped to navigate the new landscape of legal access.
\end{abstract}

Key Words: Cannabis, Medical marijuana, Government regulation, Canada

\section{INTRODUCTION}

The Marihuana for Medical Purposes Regulations (MMPR) were published in the Canada Gazette Part II as a detailed and carefully constructed 164 page document. ${ }^{[1]}$ These regulations contain information of relevance to health professionals; however, due to the length and scope, the MMPR are difficult to read quickly and to interpret readily. For consistency with the MMPR document marihuana will be used to refer to marijuana (cannabis).

The MMPR were first published by Health Canada in June 2013 to replace the Marihuana Medical Access Program (MMAP).${ }^{[1]}$ There was a transition period before they came into full effect on April 1, 2014. Since their publication there has been considerable reaction from the medical commu- nity expressing concern that the MMPR places Canadian physicians and nurse practitioners in a gatekeeper role to a controlled substance. ${ }^{[2]}$

The MMPR led to the emergence of licensed producers (LPs) of cannabis for therapeutic purposes and the creation of a medical cannabis industry that is reaching out to health professionals for commercial purposes. Health professionals with a deeper understanding of the regulatory environment surrounding cannabis for therapeutic purposes will be better equipped to engage in discussions with representatives of LPs. Health administrators and members of the allied health care team may also benefit from having a concise synopsis of these regulations to assist with discussions and shared decision making.

\footnotetext{
*Correspondence: Mark A. Ware; Email: mark.ware@ @cgill.ca; Address: A5-140.1 Montreal General Hospital, 1650 Cedar Avenue, Montreal, Quebec, H3G 1A4, Canada.
} 
This article presents a synopsis of the MMPR, specifically focusing on elements relevant for health professionals. The purpose of this paper is not to describe the risks and benefits of cannabis for therapeutic purposes but to assist health professionals to understand the structure and impact of the MMPR. An excellent review of cannabis for therapeutic purposes risks and benefits was recently published in JAMA. ${ }^{[3]}$ This paper does not address or compare the MMPR with regulatory approaches in US states (e.g. Colorado, Washington) or other countries (Israel, Holland).

\section{SYNOPSIS OF THE MMPR}

\subsection{Structure}

The regulations are divided into seven parts; the majority (parts 1, 2, 5 and 6) focus on the production and distribution of dried cannabis and are of limited relevance to health professionals. Given that herbal cannabis is not approved by the Therapeutic Products Directorate of Health Canada, it is important for health professionals to be aware that the MMPR contains extensive requirements for standards of production facilities, quality controls, necessary security measures and record keeping. For consistency with the MMPR document, the term health care professional (HCP) will be used in this synopsis to include licensed physicians and nurse practitioners. Key points are summarized in Table 1, and definitions of terms used are provided in Table 2.

\subsection{LPs (part 1)}

The standards for production, import, export and distribution of cannabis are outlined in this section of the MMPR. Note that "cannabis" in the MMPR refers to the dried herbal form; in response to a Supreme Court ruling concerning the provision of cannabis derivatives ( $\mathrm{R} v s$. Smith), on July 8 2015 Health Canada issued a section 56 exemption under the Controlled Drugs and Substances Act to allow LPs to produce and sell cannabis oil and fresh leaves. ${ }^{[4,5]}$ LPs may provide cannabis to a client, or an individual responsible for a client, or a hospital employee for the purposes of their employment. LPs may ship cannabis to a HCP only if the applicant has indicated, by means of a document signed and dated by the HCP, that they will receive the cannabis on the applicant's behalf.

Table 1. Key points from the MMPR for HCPs

\footnotetext{
1. HCPs (licensed physicians and nurse practitioners) have the authority to provide a medical document for a patient to legally access dried cannabis.

Requirements to be an LP include production facility security, satisfactory employee security checks (criminal record checks and law enforcement agency files), record keeping, and notifications to local government, police, and fire officials. Product labeling, packaging, quality assurance, testing, and recall procedures must be in place. Licenses to produce may last up to three years and can be renewed. Licenses may be suspended or revoked for failure to comply with the regulations.

\subsubsection{Adverse reactions}

Any serious adverse reaction (defined in Table 2) must be reported in the form of a case report by the LP to Health Canada within 15 days of the LP becoming aware of the reaction. LPs must also provide an annual report containing 80 concise and critical analysis of all serious adverse reactions to Health Canada for review. This has obvious implications for HCPs as it is likely that they will be the "first responders" to such adverse reactions and will need to notify the LP who provided the cannabis. There is no indication from the MMPR about specifically how the LPs will be trained to identify and report adverse events.

\subsubsection{Packaging requirements}

Packaging is to be secure, emit no odour, and designed to prevent identification of contents without being opened. Shipments are to be tracked and addressed only to the client or the person responsible for the client, in a quantity not exceeding $150 \mathrm{~g}$. 
Table 2. Definitions
1. Health care practitioner (HCP) - a medical practitioner (registered and entitled under the laws of a province to practice medicine in that province) or nurse practitioner (permitted to prescribe dried cannabis in the province in which they practice)
2. Client - person registered with a licensed producer
3. Cannabis / marihuana - Cannabis, its preparations, derivatives and similar synthetic preparations, including: Cannabis resin; Cannabis (marihuana); Cannabidiol; Cannabinol; Nabilone; Pyrahexyl; Tetrahydrocannabinol; but not including: Non-viable Cannabis seed, with the exception of its derivatives; Mature Cannabis stalks that do not include leaves, flowers, seeds or branches; and fiber derived from such stalks ${ }^{[6]}$
4. Adverse reaction - a noxious and unintended response to dried cannabis
5. Serious adverse reaction - a noxious and unintended response that require in-patient hospitalization or prolongation of existing hospitalization; that cause congenital malformation; that result in persistent or significant disability or incapacity; that are life-threatening or that result in death.
6. Case report - a detailed record of all relevant data associated with the use of dried cannabis by a person

Cannabis will be shipped with inner packaging that describes the contents as "Dried marihuana / marihuana sechée" with the percentages of delta-9-tetrahydrocannabinol (THC) and cannabidiol (CBD). The label must also state or contain the weight in grams, a scheduling symbol " $\mathrm{N}$ " for narcotic, ${ }^{[6]}$ a statement to "Keep out of reach of children", other standard medication labelling details (e.g. LP name and address, brand name, lot number, storage conditions, packaging date, expiry date or equivalent explanation), ${ }^{[7]}$ and the note "Important: Please read the Health Canada document provided with this package before using dried marihuana".

Cannabis will be shipped with additional personalized packaging and an accompanying document. The accompanying document will include: the client name and surname; the name, surname and profession of the HCP who provided the medical document; the daily quantity (grams) as indicated on the medical document; the expiry date of the client's registration; and the shipping date.

\subsubsection{Licensed producer obligations for information shar- ing}

LPs are obliged to provide to Canadian police, upon request relating to an investigation, the name of the client or individual responsible for the client, and the daily quantity specified on the medical document. LPs are also obliged to provide information about an HCP, upon request by the licensing authority responsible for the registration or authorization of the HCP's profession, for the purpose of assisting an official investigation.

\subsection{Client registration and ordering (part 2)}

The regulations do not specify who is eligible for cannabis for therapeutic purposes, including inclusion/exclusion criteria. They are also silent on mechanisms to ensure compliance including the use of urinary drug testing and contracts. These issues are raised in other clinical guidance documents. ${ }^{[8,9]}$ Clients must ordinarily reside in Canada. Clients must submit an application to the licensed producer including: Name, surname, date of birth, gender, address, telephone number, fax, and email. Clients with no dwelling place must indicate

Published by Sciedu Press the address and other information if possible of a shelter, hostel or similar institution in Canada that provides food, lodging or other social services to the applicant. Clients must indicate a mailing address, if different from their dwelling place. Clients must submit the original of their medical document to the LP. The same medical document may not be used to seek or obtain dried marihuana from more than one LP at any one time.

LPs must refuse to register an applicant as a client, or cancel a registration, if the medical document is no longer valid, if there is incorrect or suspected false application information, or if the HCP who provided the medical document notifies the licensed producer in writing that the use of cannabis by the applicant is no longer supported for clinical reasons. LPs may cancel client registrations for business reasons. If registration is refused, the medical document must be returned. If cancelled, the medical document does not get returned.

Ordering (written or verbal) must include: the date the order is made, name, surname, birthdate of client, name, surname of individual making order, shipping address, client identifier, quantity and brand name of dried cannabis being ordered. Orders must be shipped to the client, or individual responsible for the client. Part 5 of this article provides information about orders shipped to individuals responsible for the client. Producers must not sell or provide more than a 30-day quantity, to a maximum of $150 \mathrm{~g}$ at any one time.

\subsection{Clients and other authorized users (part 3)}

Proof of authorization to possess dried cannabis must be shown to police upon request. Either the label on the packaging or a separate document accompanying the shipment of dried cannabis provided by the LP can serve as the proof of legal possession. Since clients can only register with LPs with their original medical document, clients cannot obtain dried cannabis from more than one source at a time. However, a patient may access different strains offered by different LPs by obtaining two separate authorizations from his/her HCP (two separate originals). 


\subsection{Health care practitioners (part 4)}

HCPs may, in regard to a person who is under their professional treatment:

(1) Transfer or administer dried cannabis;

(2) Provide a medical document;

(3) Transfer dried cannabis to an individual responsible for the person under their professional care.

There is presently no specific training required for HCPs to be able to authorize cannabis for therapeutic purposes.

\section{Medical document}

A medical document provided by a HCP to a person who is under their professional treatment must indicate:

(1) HCP name, surname, profession, business address and telephone number, fax and email address, if applicable; and province where authorized to practice and number assigned by the province to that authorization;

(2) Patient name, surname, date of birth;

(3) Address of the location at which the person consulted with the practitioner;

(4) Daily quantity of dried cannabis to be used by the person, expressed in grams;

(5) Period of use in days, weeks or months, up to one year, beginning the day the medical document is signed by the HCP. The medical document is valid for the period of use specified in it;

(6) The HCP must sign and date and attest that the information is correct and complete.

A sample document is available on the Health Canada website. ${ }^{[10]}$ Patients may only register with one LP with a given original medical document, but they may theoretically receive more than one original medical document from an HCP and register with a different LP with each original document. There is no mechanism presently for LPs to verify whether a patient has registered with another LP. Potential medicolegal issues associated with authorizing patients have been identified and addressed by the Canadian Medical Protective Association (CMPA). ${ }^{[9]}$

Recent amendments to the MMPR ${ }^{[11]}$ provide authorization to the Minister of Health to provide a HCP's name and address to the HCP's provincial licensing body upon request. LPs must also provide this information on request. LPs may be asked provide summary information quarterly to the provincial licensing body on registered clients including name, address, HCP name, doses, and duration.

\subsection{Sale or provision by a licensed producer to a person other than a client (part 5)}

This section outlines the necessary process, signatures and information for situations where cannabis is being sold to someone other than a client. This may apply to hospital pharmacists or HCPs. HCPs cannot order on behalf of patients but patients can order and have cannabis shipped to a HCP. If a patient's cannabis is shipped to their HCP there should be no exchange of money between the patient and their HCP. The order must be signed and dated with shipping address indicated along with the quantity and brand of cannabis. When requested to ship to a person other than a client, the LP is required to verify the documentation and must provide the order by shipping. The LP must refuse the order if the requirements for shipping to a person other than a client are not met, and notify the requesting person the reason for refusal.

\subsection{Record keeping by LPs (part 6)}

Client registrations must be recorded by the producer, including registration application, medical document, and any amendments. Client orders and returns must be recorded by the LP including; information on the client and shipping details including; date, brand, quantity, and address. LPs must record all practices and production records including documents on security, production, packaging labeling, shipping and destruction. Records of testing of lots or batches must be kept. Dates and weights must be recorded throughout the production process. At the end of each quarter of the calendar year, LPs must also inventory all cannabis by the stage of production. All notices to local authorities or the Minister must also be recorded. Records must be kept accessible for auditing at their site for a period of two years and must be provided to Health Canada at any time that the Minister of Health requests. Case reports and summary reports of serious adverse reactions must be kept for 25 years after the date they are made.

\subsection{Transition to the MMPR (part 7)}

Amendments to the Narcotic Control Regulations are here described to accommodate the new MMPR. The Narcotic Control Regulations includes requirements for HCPs, pharmacists and hospitals to conduct activities with narcotics. Cannabis is a narcotic, so amendments were made to ensure that cannabis fit (as much as possible) within that regime. For example, signing the medical document under the MMPR is treated the same as prescribed narcotics under the Narcotic Control Regulations, and Health Canada has the authority to share information with Colleges during investigation of HCPs.

\section{AdVERTISING}

Health professionals should be aware that advertisements about cannabis for therapeutic purposes must comply with the MMPR, Narcotic Control Regulations and the Food and Drugs Act. ${ }^{[12,13]}$ A warning letter was issued on November 
$25^{\text {th }} 2014$ by Health Canada to address concerns regarding false, misleading or deceptive advertisements about specific therapeutic effects of cannabis and the use of Health Canada as an endorsement of their products. ${ }^{[12]}$

Advertisements may only include basic information for prospective clients such as the brand name, proper or common name of the strain, the price per gram, the cannabinoid content and the company's contact information. ${ }^{[12]}$ A reporting mechanism for concerns from the public has been placed on the Healthy Canadians website. ${ }^{[12]}$

\section{IMPACT}

This synopsis captures key points from Canada's MMPR relevant for health professionals. Recognizing the standards of medical cannabis production in Canada and obligations of the producers will assist health professionals navigate the new medical cannabis landscape. Becoming familiar with how adverse reactions are reported, what the medical document authorizing medical cannabis must include, and what the actual packaging indicates will enable health professionals to engage in more meaningful and informed discussions with patients. Although aimed at enabling time-strapped health professionals to gain an understanding, this synopsis may also stimulate interest in reading the MMPR; which is encouraged for those with the time and determination. It is important to remain cognisant that this synopsis is not intended to describe the risks and benefits or provide clinical practice guidance. In general, this synopsis enables health professionals to gain a deeper understanding of these regulations without devoting extensive time to locate, read, and digest the full document.

\section{REFERENCES}

[1] Marihuana for Medical Purposes Regulations. Controlled Drugs and Substances Act [Internet]. Part II, June 19, 2013. Available from: http://gazette.gc.ca/rp-pr/p2/2013/2013-06-19/ html/sor-dors119-eng.php

[2] CMA Response: Health Canada's Medical Marihuana Regulatory Proposal. Controlled Drugs and Substances Act [Internet]. Feb 28, 2013. Available from: https://www.cma.ca/Assets/assets-1 ibrary/document/en/advocacy/Proposed-Medical-Marih uana-Regulations_en.pdf

[3] Whiting PF, Wolff RF, Deshpande S, et al. Cannabinoids for Medical Use: A Systematic Review and Meta-analysis. JAMA. Jun 2330, 2015; 313(24): 2456-73. http://dx.doi.org/10.1001/jam a. 2015.6358

[4] Statement on Supreme Court of Canada Decision in R. vs. Smith. Available from: http://www.hc-sc.gc.ca/dhp-mps/marihua na/info/licensedproducers-producteursautorise/dec ision-r-vs-smith-eng.php

[5] Controlled Drugs and Substances Act [Internet]. Schedule II, Item 1. Available from: http://laws-lois.justice.gc.ca/eng/ac ts/c-38.8/page-25.html\#h-29

[6] C.R.C., c. 1041. Narcotic Control Regulations [Internet]. Available from: http://laws-lois.justice.gc.ca/eng/regula tions/C.R.C.,_c._1041/FullText.html

[7] Draft Guidance Document Labelling of Pharmaceutical Drugs for Human Use. Health Canada [internet]. Available from: http://www.hc-sc.gc.ca/dhp-mps/prodpharma/applic-d emande/guide-ld/label_guide_ld-eng.php
[8] Sample Medical Document for the Marihuana for Medical Purposes Regulations. Health Canada [internet]. Available from: http://www.hc-sc.gc.ca/dhp-mps/alt_formats/pdf /marihuana/info/med-eng.pdf

[9] Canadian Medical Protective Association. Medical marijuana: New regulations, new College guidance for Canadian doctors. Available from: https://www.cmpa-acpm.ca/en/legal-and-regulat ory-proceedings/-/asset_publisher/a9unChEc2NP9/con tent/medical-marijuana-new-regulations-new-college -guidance-for-canadian-doctors

[10] College of Family Physicians of Canada. Authorizing dried cannabis (medical marijuana) for chronic pain or anxiety: preliminary guidance. Available from: http://www.cfpc.ca/uploadedFile s/Resources/_PDFs/Authorizing\%20Dried\%20Cannabis $\% 2$ Of or $\% 20$ Chronic $\% 20$ Pain $\% 20$ or $\% 20$ Anxiety.pdf

[11] Regulations Amending the Narcotic Control Regulations and the Marihuana for Medical Purposes Regulations (Communication of Information). Canada Gazette [Internet]. June 17, 2015; 149(12). Part II. Available from: http://gazette.gc.ca/rp-pr/p2/201 5/2015-06-17/html/sor-dors132-eng.php

[12] Information Update - Marijuana for Medical Purposes - Advertising and Licensed Producers. Healthy Canadians [Internet]. November 25, 2014. Available from: http: //www.healthycanadians.gc.ca/recall-alert -rappel-avis/hc-sc/2014/42677a-eng.php

[13] Drugs and health products: Advertising prohibitions pertaining to marijuana. Health Canada [Internet]. November 25, 2014. Available from: http://www.hc-sc.gc.ca/dhp-mps/marihuana/info/ bulletin-eng.php 